\title{
Pemaknaan fashion: Studi gaya hidup pada komunitas Indonesia Sneakers Team Surabaya
}

\author{
The use of fashion: Study of lifestyle in the Indonesian Sneakers Team \\ Surabaya community
}

\author{
Satrio Manggala Putra Sahrub \\ Departemen Sosiologi, Fakultas Ilmu Sosial dan Ilmu Politik, Universitas Airlangga \\ Surabaya, 60286, Jawa Timur, Indonesia \\ E-mail: satrio.manggala.p.s.-2014@fisip.unair.ac.id
}

\begin{abstract}
Abstrak
Fashion menjadi bagian yang tidak dapat dilepaskan dari penampilan dan gaya keseharian dan telah menjadi identitas sesorang. Identitas sosial seseorang terbentuk melalui proses sosial sehingga membedakannya dengan orang lain dilihat dari ciri-ciri sosial seperti kebiasaan berpakaian, kebiasaan mengisi waktu luang, kebiasaan berbelanja dan sebagainya. Penelitian ini bertujuan untuk mendeskripsikan makna mode sebagai bentuk identitas sosial dan gaya hidup di Tim Sepatu Surabaya. Penelitian ini dilakukan di komunitas Tim Indonesia Sneakers Surabaya. Untuk menjawab masalah dalam penelitian ini digunakan teori Jean Baudrillard dan hyperreality dogma Leisure Class oleh Thorsten Veblen. Penelitian ini menggunakan model definisi sosial dengan teknik purposive untuk mendefinisikan informan. Informan dalam anggota komunitas penelitian adalah sepuluh sepatu tim Indonesia Surabaya. Metode pengumpulan data dalam penelitian ini adalah wawancara mendalam dan observasi di lapangan telah dianalisis dengan melalui proses pengumpulan data, kehilangan data, data presentasi, tipe data dan penarikan kesimpulan. Hasil yang ditemukan antara lain: Tim Sepatu Indonesia Surabaya adalah sekelompok orang yang hobi mengumpulkan sepatu dari berbagai merek. Komunitas ini lahir melalui forum di satu media sosial. Seorang anggota komunitas yang telah berpartisipasi dalam penerimaan konsumen karena nilai baru yang terjadi di setiap komunitas aktif yang bertemu dengan tim Indonesia. Selain itu, anggota komunitas terinspirasi oleh idola mereka dan diamati di media sosial untuk band. Fashion dimaksudkan untuk menjadi hobi, mengidentifikasi dan membangun citra yang baik di masyarakat.
\end{abstract}

Kata kunci: identitas sosial; fashion; tim sepatu Indonesia; gaya hidup; media

\begin{abstract}
Fashion becomes an inseparable part of daily appearance and style and has become someone's identity. A person's social identity is formed through social processes that are different from others as seen from social characteristics such as dress habits, leisure time habits, shopping habits and so on. This study aims to description the meaning of fashion as a form of social identity and lifestyle in Indonesia Sneakers Team Surabaya. This research was done in the communities of Indonesia Sneakers Team Surabaya. To answer the problem in this study used a theory of Jean Baudrillard and hyperreality dogma Leisure Class by Thorsten Veblen. This study uses a social definition model with techniques purposive To define informants. The informant in the research community members is the ten Indonesian Surabaya team sneakers. Methods of gathering data in this study are in deep interviews and observations in the field have been analyzed with through the process of data collection, data loss, presentation data, data types and conclusion recall. The results found among others: Indonesian Sneakers Team Surabaya is a group of people whose hobbies are collecting shoes from a variety of brands. This community was born through a forum on one social media. A community member who has participated in consumer acceptance due to the new value occurs in any active community meeting the Indonesia team sneakers. In addition, community members inspired their idol and observed in social media for the band. Fashion is meant to be a hobby, identify and build a good image on the public.
\end{abstract}

Keywords : identity society; fashion; Indonesia Sneakers Team; lifestyle; media

\section{Pendahuluan}

Fashion menjadi bagian yang tidak dapat dilepaskan dari penampilan dan gaya keseharian (Black 2009). Benda-benda seperti baju dan aksesoris yang dikenakan bukanlah sekadar penutup tubuh dan hiasan, lebih dari itu juga menjadi sebuah alat untuk menandakan identitas sosial pribadi (Sweetman 1999; Davis 2013; Entwistle 2015). Fashion bisa menjadi etalase kecil tentang diri seseorang bagi orang lain dan gaya berpakaian atau berbusana merupakan sebuah bahan penilaian awal seseorang. 
Dalam perkembangan selanjutnya fashion tidak hanya menyangkut soal busana dan aksesoris semacam perhiasan seperti kalung dan gelang, akan tetapi benda-benda fungsional lain yang dipadukan dengan unsur-unsur desain yang canggih dan unik menjadi alat yang dapat menunjukkan dan mendongkrak penampilan si pemakai (Hendariningrum \& Susilo 2014).

Berbusana merupakan hal yang tidak akan pernah lepas dari perhatian setiap individu, karena hal ini bisa menjadi penilaian tersendiri dari orang lain terhadap karakter masing-masing individu tersebut. Dulu busana merupakan kebutuhan, namun seiring berkembangnya zaman, busana tidak lagi sekedar pemenuhan kebutuhan saja, akan tetapi juga menjadi sebuah kehendak dalam memenuhi cita rasa si pemakai (Barthes 1983; Craik 2003). Busana menunjukkan siapa pemakainya sebagaimana dikatakan Umberto Eco 2014 dalam bukunya Tamasya dalam hiperrealitas yang menyatakan "I speak through my clothes" (aku berbicara lewat busanaku).

Karim (2016) mendefinisikan busana atau pakaian yang kita kenakan dapat diartikan menampilkan pesan, penyingkap identitas sosial sebagai personal maupun identitas sosial kelompok melalui berbagai macam interaksi sosial. Persoalan berbusana sebagai identitas merupakan bentuk dialektika sosial dalam mengartikulasikan realitas. Busana menyampaikan pesan-pesan dan merupakan pencitraan untuk menegaskan berbagai fungsi-fungsi sosial dalam transformasi sosial (Barnard 2010; Hinton 2013). Selain itu, busana juga berfungsi untuk menampilkan status sosial dan standardisasi norma melalui penggunaannya (Fionda \& Moore 2009). Memilih busana dalam ruang-ruang tertentu, rumah, kantor, atau kampus maupun komunitas merupakan bentuk sense of fashion tanpa menampik fungsi sosial lain semacam kesepakatan aturan atau norma.

Persoalan bagaimana memilih fashion dan menggunakannya dalam kehidupan sehari-hari sebenarnya merupakan pilihan gaya hidup (Kaiser, 1997; Calefato, 2014). Kebiasaan-kebiasaan baru pada akhirnya melahirkan identitas sosial tertentu yang melekat pada orang bersangkutan, baik disadari oleh orang itu sendiri ataupun tidak. Identitas sosial tidak dapat dinyatakan secara sepihak oleh orang itu sendiri, tetapi merupakan hasil dari persepsi masyarakat di sekitar dirinya. Dengan demikian, identitas sosial pada dasarnya merupakan proses produksi budaya yang terus berlangsung sehingga proses terbentuknya identitas sosial tidak bersifat final seperti halnya identitas biologis manusia yaitu lakilaki atau perempuan.

Terkait fashion dan identitas, Rahardjo dan Silalahi (2007) menyatakan bahwa pria metroseksual lebih dari sekedar fakta melainkan juga sebuah fenomena yang kian menggejala di hampir semua kota besar dewasa ini. Pria metroseksual adalah pria yang women oriented dan memiliki karakteristik unik seperti narsis dan merawat dirinya seringkali melebihi apa yang dilakukan oleh wanita, yaitu bisa membeli apapun yang diinginkan untuk memenuhi kebutuhan yang berkaitan dengan pekerjaan dan penampilan.

Hal ini didukung oleh penelitian Pambayun 2017 bahwasannya adanya waktu luang dapat memberikan peluang untuk terjadinya kegiatan konsumsi. Hal seperti ini dapat terjadi ketika para atlet basket menghabiskan waktu luangnya untuk pergi ke pusat perbelanjaan, tempat wisata maupun tempat hiburan lainnya. Terdapat penelitian yang dilakukan oleh salah satu biro pemasaran ternama yaitu MarkPlus\&Co yang dilakukan di Jakarta pada tahun 2003 mengenai fenomena gaya hidup metroseksual. Survey tersebut melibatkan 400 responden pria dari ekonomi kelas atas (berpengeluaran lebih dari Rp. 5 juta perbulan), dengan rentang usia 26-55 tahun. Dalam survey tersebut ditemukan bahwa $35 \%$ dari responden mengaku bahwa aktivitas belanja dijadikan sebagai aktivitas belanja sebagai rekreasi. Mereka tidak lagi berbelanja sesuai dengan kebutuhan seperti pria konvensional (Mulyana 2005).

Gaya hidup dapat membentuk identitas sosial yang berbeda dari setiap orang. Perbedaan tersebut muncul melalui perilaku konsumsi individu. Individu akan menjaga tindakan-tindakannya secara terpola demi memenuhi identitas sosial yang diinginkan (Chua 2002; Scott 2006). Citra diri merupakan suatu hal yang dikonsumsi secara terus menerus dan tak pernah terpuaskan. Konsumsi adalah satu proses perubahan yang secara historis dikonstruksi secara sosial (Suyanto 2013). Gaya 
hidup pria metroseksual adalah gaya hidup pria yang merupakan imbas dari kehidupan sosial dengan memiliki gaya hidup seperti layaknya wanita. Pria metroseksual memiliki gaya hidup yang mengarah pada belanja di mall atau butik bukan untuk purpose shopping, tetapi lebih ke pleasure shopping. Gaya hidup pria metroseksual juga berupa menghabiskan banyak waktu di kafe-kafe, bahkan juga memilih untuk melajang sampai usia tertentu (Handoko 2004).

Menurut penelitian Dharmawan (2017) bahwa sepatu sneakers saat ini tidak hanya bermanfaat dalam bidang sarana penunjang kehidupan fashion yang stylish di kalangan mahasiswa UNESA Surabaya akan tetapi sebagai simbol kebangaan serta gengsi mengingat harganya yang mahal. Selain itu, dengan memakai sepatu sneakers dapat membantu pemakainya meningkatkan rasa kepercayaan diri karena pemakaianya tidak perlu lagi mengkhawatirkan tentang gaya busananya ketika sedang berinteraksi dalam suatu kelompok sosial. Sepatu menjadi tren lifestyle baru yang menjamur di kalangan masyarakat Indonesia. Tidak heran bahwa sepatu menjadi atribut penting pada diri individu dalam menentukan gaya berbusana. Dampaknya sering dijumpai di tempat-tempat umum, seperti: kampus, jalan umum, serta mal. Bahkan, pengguna sepatu sangat beragam dari berbagai merk terkenal di dunia. Hal tersebut menandakan bahwa sepatu memiliki peran penting mengenai persoalan fashion saat ini. Tren ini bukan tren yang akan segera pudar, tetapi semakin berkembang pesat.

Sementara itu, Kota Surabaya merupakan kota yang terdiri dari berbagai komunitas sepatu dari berbagai merek. Diantaranya Vans, Macbeth, Converse, Adidas, Air Jordan, New Balance. Biasa kita kenal dengan nama Vanshead Surabaya, Griffons Army Surabaya, Converse Head Indonesia, Trefoil Surabaya dan lain-lain. Komunitas awalnya sebagai tempat untuk berbagi pengalaman historis dan sarana transaksi jual beli antar anggota, namun semakin berkembang menjadi tempat pembentuk identitas sosial, gaya hidup dan leisure class.

Perkembangan gaya berbusana atau fashion pada komunitas Indonesia Sneakers Team Surabaya menjadi sangat masif dan cepat. Hal tersebut dikarenakan pesatnya tren berbusana yang menjamur di dunia yang dapat dengan mudah diakses melalui alat komunikasi. Perubahan gaya berbusana sesuai tren yang sedang berkembang dapat dengan mudah dijumpai di dalam komunitas. Perubahan tersebut tentu membutuhkan alokasi dana yang besar. Gaya hidup berkaitan dengan pola konsumsi yang mencerminkan pilihan seseorang dalam menghabiskan waktu dan uang. Pria metroseksual dalam komunitas Indonesia Sneakers Team Surabaya berbelanja tanpa didasari pertimbangan karena tergoda hasrat untuk mengikuti tren yang sedang berlaku dan tak disadari bahwa barang yang dibeli merupakan bukan kebutuhan yang sebenarnya dikenal dengan perilaku konsumtif.

Perilaku konsumtif merupakan tindakan-tindakan individu yang secara langsung terlibat dalam usaha memperoleh dan menggunakan jasa-jasa ekonomis termasuk di dalamnya proses pengambilan keputusan yang mendahului dan menentukan tindakan tersebut (Turner 2006; Featherstone 2007). Pria metroseksual menyukai perilaku konsumtif demi memenuhi hasratnya untuk membentuk identitas sosial yang diharapkan. Mulai dari atribut kepala hingga kaki semuanya diperhatikan demi identitas sosial yang ingin diperoleh. Pada era masyarakat konsumen, waktu senggang menjadi kebutuhan tersendiri masyarakat, tidak hanya untuk melepas kepenatan, tetapi juga menjadi cara untuk mengekspresikan simbol-simbol dan gaya hidup yang membedakan mereka dengan kelas sosial yang lain.

Untuk menganalisis fokus penelitian yang telah disampaikan di atas, peneliti menggunakan teori konstruksi sosial yang dikemukakan oleh Jean Baudrillard dan Thorsten Veblen. Menurut Baudrillard, yang disebut sebagai dunia hiper-realitas atau dunia yang melampaui realitas (hyper-reality) pada dasarnya adalah sebuah realitas yang bersifat artifisial atau superfisial, yang tercipta lewat bantuan teknologi simulasi dan rekayasa pencitraan, yang mengambil alih dunia realitas yang alamiah. Hiperrealitas merupakan model-model realitas, yang tidak memiliki referensi pada realitas. Hiper-realitas tidak memliki rujukan atau referensi pada realitas melainkan merujuk pada dirinya sendiri (selfreference) (Baudrillard 2006). 
Baudrillard melihat post-modern sebagai suatu trend dan sebagai awal dari suatu era baru yang dibawa oleh makin maraknya komunikasi bermediasi, konsumsi simbolis, dan semakin mampatnya ruang dan waktu. Peran media terutama budaya popular dan iklan yang signifikan, "menurut Baudrillard melahirkan referensialitas-diri pada tanda-tanda dan munculnya keteraturan tatanan sosial yang didasarkan pada konsumsi simbolis" (Suyanto 2013).

Jean Baudrillard menggambarkan kehidupan post-modern ini sebagai hiper-realitas. Media berhenti menjadi cerminan suatu realitas sosial, tetapi justru menjadi realitas itu sendiri. Media sosial, surat kabar, TV, internet merupakan sebuah contoh yang baik karena sebuah kebohongan dan distorsi yang disajikan kepada pemirsa melebihi realitas. Distorsi dan kebohongan itu yang dimaksud sebagai hiperrealitas. Mengakibatkan apa yang nyata disubordinasikan dan akhirnya dilarutkan sama sekali, sehingga mustahil membedakan yang nyata dan yang menjadi tontonan. "Dalam kehidupan nyata, kejadian-kejadian nyata semakin mengambil ciri hiper-real dan tidak ada lagi realitas, yang ada hanyalah hiper-realitas" (Suyanto 2013).

Dunia menurut Baudrillard adalah simulakra. Maksudnya adalah dominasi simulakra dalam kehidupan modern saat ini hampir ada dalam setiap aktivitas manusia seperti iklan, televisi, produk supermarket dan juga didukung adanya pusat perbelanjaan. Tidak adanya perbedaan antara realitas asli dengan realitas semu atau buatan inilah yang mendominasi masyarakat saat ini. Sehingga dapat dengan mudah masyarakat dikelabui dengan iklan, promo dan rilisan produk terbaru dari brand ternama di dunia. Baudrillard mengambil contoh pada fenomena adanya Disneyland yang merupakan bagian dari dominasi simulakra. Masyrakat dapat rela mengantri untuk masuk dan melihat isi di dalam Disneyland yang semata-mata hanya sebagai pemuas nafsu dan hasrat. Betapa mudahnya dunia imajiner dibentuk dan meraih hati mayoritas masyarakat untuk datang ke tempat tersebut dan bahkan menghabiskan uang di dalamnya. Menurut Jean Baudrillard Fenomena yang terjadi di dalam dunia simulasi adalah ketidakmampuan membedakan antara fakta dan citra. Kedua hal tersebut menyatu menjadi satu kesatuan yang tidak dapat dipisah, susah membedakan mana yang asli dan mana yang palsu. Keseluruhan hal tersebut menjadi bagian dari realitas yang dialami oleh masyarakat post-modern saat ini (Baudrillard 2006).

Menurut Thorsten Veblen dalam bukunya The Theory of Leisure Class, apa yang diperhatikan masyarakat hanyalah uang. Karena kepemilikan uang atau harta mampu menaikan derajat, status sosial, harga diri dan gengsi seseorang dalam masyarakat. Dengan harta yang berlimpah seseorang akan berusaha membeli barang-barang yang nantinya digunakan sebagai alat pamer. Pada kehidupan saat ini, tingkat kecenderungan memamerkan harta kekayaan semakin tinggi (Deliarnov 2005).

The Leisure Class ini berangkat dari pemikiran salah satu tokoh Sosiologi, yaitu Thorstein Veblen. Berasal dari kata leisure yang berarti "waktu luang" dan berarti leisure class sendiri teori yang menjelaskan tentang perilaku seseorang dalam memanfaatkan waktu luang mereka. Definisi leisure class sendiri ada hubungannya dengan waktu luang. Pada akhirnya istilah "leisure class" diterjemahkan menjadi kelas pemboros. Dari beberapa pengertian yang berbeda-beda pada akhirnya jika dihubungkan akan menghasilkan makna tentang leisure class. Jadi, apabila dari beberapa pengertian istilah tersebut dijadikan satu, maka leisure class itu berarti suatu kelas pemboros yang mengeluarkan banyak uang demi mewujudkan keinginan untuk memenuhi waktu luangnya (Fika Okiriswandani 2013).

\section{Metode Penelitian}

Tipe penelitian yang digunakan oleh peneliti yaitu tipe kualitatif dengan menggunakan pendekatan berperspektif fenomenologi. Tipe penelitian kualitatif digunakan untuk mencari jawaban mengenai masalah yang dicari sehingga akan ditemukan jawaban yang sejelas-jelasnya dari informan dan memperoleh gambaran yang nyata mengenai suatu kejadian menurut pandangan informan yang diteliti. 
Teknik penentuan informan dalam penelitian ini yaitu peneliti menggunakan teknik purposive untuk mendapatkan informan yang dirasa tepat untuk menjawab dan memiliki wawasan yang luas mengenai permasalahan penelitian tersebut. Dalam penelitian ini, kriteria yang harus dipenuhi sehingga dapat menjadi informan yang dapat diwawancara, yaitu seorang anggota komunitas Indonesia Sneakers Team yang baru saja bergabung dan anggota komunitas yang sudah lama bergabung. Sedangkan untuk pengumpulan data dalam penelitian ini yaitu dilakukan wawancara mendalam (indepth interview) dengan menggunakan pedoman wawancara agar dapat memperoleh data secara lebih rinci yang berkaitan dengan topik penelitian.

\section{Hasil dan Pembahasan}

\section{Pemaknaan fashion sebagai identitas sosial}

Sepatu dengan fashion merupakan satu kesatuan yang saling terkait dan melengkapi. Setiap seseorang yang memperhatikan penampilan otomatis juga memberi perhatian khusus bagi bagian kakinya dengan sepatu yang bagus. Pada awalnya, sepatu hanya digunakan seseorang hanya sebagai pelengkap kebutuhan dan sekedar alas kaki. Namun, seiring perkembangan sepatu sneakers tidak hanya digunakan sebagai alas kaki saja, tetapi sepatu sneakers juga dipakai sebagai penunjang penampilan dan jati diri seseorang. Hal inilah yang menjadikan interaksi sosial antara anggota komunitas Indonesia Sneakers Team Surabaya menciptakan pemikiran baru mengenai makna fashion. Anggota komunitas mendapatkan pemikiran baru setelah bergabung dalam komunitas Indonesia Sneakers Team Surabaya. Peneliti menemukan makna yang berbeda-beda mengenai fashion sebagai identitas sosial.

Informan EG yang ingin menjadi seseorang yang tidak terlalu dominan didalam komunitas. Tetapi ia tetap memperhatikan penampilannya dan selalu mengembangkan gaya busanananya. Informan EG memaknai fashion sebagai identitas sosialnya untuk menaikan status dan agar diperhatikan oleh orang lain. Sedangkan informan FA yang sebelum bergabung dengan komunitas dikenal memiliki penampilan yang biasa saja. Namun setelah bergabung dengan Indonesia Sneakers Team Surabaya mengubah penampilan dan fashionnya. Makna fashion bagi identitas sosialnya adalah sebagai citra diri dan memperoleh status sosial yang diinginkan oleh informan. Informan FA sekarang dikenal sebagai seseorang yang selalu menampilkan gaya busana mewah. Itu terlihat dari ragam busana bermerek mahal yang informan kenakan. Selanjutnya informan SB yang menganggap fashion adalah sebagai pelengkap dan penunjang keseharian. Informan SB memaknai fashion sebagai suatu jati diri yang ia tampilkan. Informan SB ingin dinilai apa adanya. Maka dari itu ia mengenakan gaya busana yang menjadi kegemaran dan memunculkan rasa kenyamanan bagi dirinya. Selain itu informan SB tidak mementingkan seberapa mahal fashion yang ia kenakan karena ia beranggapan dalam berbusana harga tidak berpengaruh.

Fashion dapat juga dimaknai sebagai penyalur hobi (Wolfinbarger \& Gilly 2001). Lewat komunitaslah hobi tersebut dapat dikembangkan. Informan TR memaknai fashion sebagai bentuk penyalur hobi dan kegemarannya mengenai fashion dan berbusana. Informan TR menganggap dengan masuk ke dalam komunitas ia dapat memperluas wawasan dan ilmu mengenai fashion dan sepatu sneakers. Sedangkan bagi informan PA memaknai fashion sebagai cara untuk menunjukan identitas dan jati dirinya kepada orang lain. Informan PA tidak mempermasalahkan bagaimana penilaian orang lain terhadapnya karena ia terfokus pada gaya busana yang ia suka dan kenakan sehari-hari. Beda lagi bagi informan RR yang memaknai fashion sebagai tujuan untuk menarik perhatian orang lain.

Informan RR berkeyakinan dengan gaya busana yang ia kenakan dapat menarik perhatian orang lain maupun lawan jenis. Maka dari itu ia mengenakan fashion yang dapat membantu dirinya meraih tujuan tersebut. Berbeda lagi dengan informan AH yang memaknai fashion sebagai suatu hal yang dapat membantu menaikan status sosial. Hal ini dikarenakan dari penilaian yang dianut masyarakat mengenai suatu barang dari berbagai macam merek terkenal. Selain itu informan AH setuju apabila seseorang yang selalu tampil bagus di depan publik dan didukung dengan berbagai macam merek fashion yang dikenakan dapat menciptakan identitas sosialnya. 
Keterkaitan analisis pertanyaan tersebut dengan salah satu teori yang digunakan adalah teori hiperealitas dari Jean Baudrillard. Menurut Jean Baudrillard yang disebut sebagai dunia hiper-realitas atau dunia yang melampaui realitas (hyper-reality) pada dasarnya adalah sebuah realitas yang bersifat artifisial atau superfisial, yang tercipta lewat bantuan teknologi simulasi dan rekayasa pencitraan, yang mengambil alih dunia realitas yang alamiah. Hiper-realitas merupakan model-model realitas, yang tidak memiliki referensi pada realitas. Hiper-realitas tidak memliki rujukan atau referensi pada realitas melainkan merujuk pada dirinya sendiri (self-reference) (Baudrillard 2006).

Dari beberapa pertanyaan dan jawaban yang muncul, informan menjawab bahwa makna fashion bagi identitas sosial dan gaya hidup mereka merupakan suatu yang sangat penting bagi masing-masing informan. Jawaban yang hampir sama dengan informan lainnya yang menyatakan bahwa makna fashion baginya adalah sebagai bentuk pencitraan diri di hadapan orang lain yang bertujuan untuk dilihat, diamati dan berharap menjadi contoh bagi penontonnya. Sebagian informan menjawab agar dirinya diakui keberadaannya pada lingkungan di mana ia berada. Jati diri merupakan alasan utama informan membentuk identitas sosialnya melalui fashion. Tidak menutup kemungkinan informan memiliki tujuan lain seperti adanya tawaran pekerjaan yang dialami oleh salah satu informan. Salah satu bentuk pengakuan yang ada pada komunitas Indonesia Sneakers Team Surabaya dikenal dengan istilah anak lama dan hype. Anak lama merupakan istilah bagi mereka yang sudah lama terjun kedalam dunia sepatu dan biasanya diisi oleh orang-orang yang sudah aktif pada forum cikal bakal terbentuknya Indonesia Sneakers Team Surabaya.

Hal yang sama terjadi pada pemaknaan fashion pada komunitas Indonesia Sneakers Team Surabaya, dimana anggotanya berusaha menampilkan jati dirinya sebagus mungkin, setinggi mungkin di hadapan anggota yang lain. Informan tidak akan menampilkan jati diri sehari-harinya dihadapan anggota komunitas. Namun informan lebih memilih menampilkan dirinya dengan barang yang mewah, mahal dan kekinian. Fenomena seperti ini berbanding terbalik dengan kehidupan aslinya yang masih makan seadanya, dan tidak terpenuhinya berbagai macam kebutuhan primer. Seperti informan FRS yang menjadikan kebutuhan sekunder bahkan tersier menjadi kebutuhan primer, sedangkan kebutuhan primernya disampingkan. Selain itu informan mencitrakan dirinya lewat postingan akun media sosial Instagram dengan postingan seputar gaya berbusananya. Tentu dengan foto kekinian, editan filter foto dan komposisi dari barang yang dikenakan menjadi nilai lebih. Sebuah fenomena hiperealitas pada lingkungan komunitas sepatu di kota Surabaya.

Keterkaitan analisis pertanyaan tersebut dengan salah satu teori yang digunakan adalah teori Leisure Class oleh Thorsten Veblen mengenai kelompok sosial yang memiliki waktu luang. Waktu luang yang digunakan oleh informan dengan mengikuti agenda pertemuan yang diadakan oleh komunitas Indonesia Sneakers Team Surabaya memberi pengaruh yang cukup signifikan yaitu informan mulai mengenal banyak informasi mengenai sepatu sneakers dan fashion. Karena cukup memiliki wawasan mengenai dunia sepatu, informan mulai mencari ragam fashion yang sesuai dengan seleranya. Sehingga dengan mudah ia mencari dan menentukan keputusan untuk membeli suatu barang.

Pemanfaatan waktu luang pada komunitas Indonesia Sneakers Team Surabaya yang digunakan untuk melakukan pertemuan dengan antar anggota komunitas memberi dampak bagi informan sebagai anggota komunitas baru di Indonesia Sneakers Team Surabaya. Informan menjadi konsumtif dan gemar mengeksplorasi gaya fashion-nya. Namun ada beberapa informan yang sejak sebelum bergabung dengan komunitas sudah konsumtif dan dari keluarga yang berstatus ekonomi atas. Sehingga informan tidak terkena dampak dari agenda pemanfaatan waktu luang yang sering dilakukan oleh komunitas Indonesia Sneakers Team Surabaya. informan dalam kategori ini memang sejak awal sudah konsumtif.

\section{Simpulan}

Fashion merupakan salah satu cara bagi masyarakat modern untuk menampilkan identitas sosial. Khususnya pada komunitas Indonesia Sneakers Team Surabaya yang terfokus pada koleksi sepatu sneakers. Sepatu sneakers saat ini tidak hanya berperan sebagai pelengkap penampilan saja, lebih dari 
itu dapat menampilkan identitas pribadi pemakainya. Gaya hidup informan ketika bergabung dengan komunitas Indonesia Sneakers Team Surabaya mengalami perubahan menjadi lebih konsumtif dari sebelumnya. Dikarenakan informan sudah memiliki wawasan yang cukup mengenai sepatu sneakers baik dari jenis sepatu, tempat membeli dan sepatu apa yang sedang tren pada saat itu. Namun ada informan yang memang sejak sebelum bergabung sudah konsumtif dikarenakan kemampuannya secara sisi finansial.

Pada proses informan secara tidak langsung mengalami dampak dari hiperealitas. Kemudian informan berusaha menciptakan identitas sosial dirinya sesuai dengan idola yang mereka inginkan. Mulai dari sini informan menciptakan identitas sosialnya sesuai dengan apa yang ia sukai. Namun informan tidak menyadari bahwasannya apa yang telah ia lakukan adalah sebuah hiperealitas yang berusaha mengidentitaskan dirinya dengan citra sebagus mungkin dan terus-menerus membentuknya lewat aktivitas konsumsi yang masif. Dari semua informan yang telah peneliti wawancarai, hanya beberapa informan yang memaknai fashion sebagai identitasnya sebagai hobi yang disalurkan lewat kepemilikan sepatu. Informan pada kategori ini tidak mengharapkan status sosial yang tinggi dan nilai lain dari kepemilikan sepatu dan segala macam barangnya. Informan hanya sekedar memiliki dan memakai barang yang ia sukai. Selain itu, terdapat informan yang masuk dalam kategori konsumtif karena dirinya dapat disebut sebagai kolektor sepatu. Namun yang membedakannya adalah dirinya tidak memamerkan apa yang ia miliki dengan berbagai macam alasan. Selain itu informan ini tetap mengutamakan sepatu dan barang yang nyaman ketika dipakai bukan melihat sisi prestisius suatu barang. Para informan yang memaknai fashion sebagai bentuk identitas sosialnya sebagai bentuk jati diri dan membangun citra yang bagus didepan umum.

\section{Daftar Pustaka}

Barnard M (2009) Fashion sebagai Komunikasi. Yogyakarta \& Bandung: Jalasutra.

Barnard M (2010) Fashion statements: Communication and culture. In Fashion Statements (pp. 2334). Palgrave Macmillan, New York.

Baudrillard JP (2006) Masyarakat Konsumsi. Cetakan ke-2. Yogyakarta: Kreasi Wacana.

Black S (2009) Editorial in fashion practice. The Journal of Design, Creative Process and the Fashion Industry 1 (1):5-8.

Barthes R (1983) The fashion system (p. 243). Berkeley: University of California Press.

Chua BH (Ed.) (2002) Consumption in Asia: Lifestyle and Identities. Routledge.

Davis F (2013) Fashion, Culture, and Identity. University of Chicago Press.

Dharmawan OP (2017) Fenomena sneakers impor (Studi konstruksi sosial pemakai sneakers impor Universitas Negeri Surabaya). Jurnal Paradigma 5 (1).

Eco U (2004) Tamasya Dalam Hiperealitas. Jakarta: Jalasutra.

Entwistle J (2015) The Fashioned Body: Fashion, Dress and Social Theory. John Wiley \& Sons.

Featherstone M (2007) Consumer Culture and Postmodernism. Sage.

Fionda AM \& Moore CM (2009) The anatomy of the luxury fashion brand. Journal of brand Management 16 (5-6):347-363.

Handoko CT (2004) Metroseksualitas dalam iklan sebagai wacana gaya hidup posmodern. Nirmana 6 (2):132-142.

Hendariningrum R \& Edy S (2008) Fashion dan Gaya Hidup: Identitas dan Komunikasi. Theses: Universitas Pembangunan Nasioanl Veteran Yogyakarta.

Hinton PR (2013) Returning in a different fashion: culture, communication and changing representations of 'Lolita' in Japan and the West. International Journal of Communication 7 (21).

Kaiser SB (1997) The Social Psychology of Clothing: Symbolic Appearances in Context. Fairchild. New York.

Mulyana D (2005) Ilmu Komunikasi Suatu Pengantar. Bandung: PT Remaja Rosdakarya.

Scott B (2006) Scottish café society: Contemporary consumption issues and lifestyle identities. International Journal of Contemporary Hospitality Management.

Suyanto B (2013) Sosiologi Ekonomi: Kapitalisme dan Konsumsi di Era Maysrakat Post-Modernisme. Jakarta: Prenada Media Kencana. 
Sweetman P (1999) Anchoring the (postmodern) self? Body modification, fashion and identity. Body \& Society 5 (2-3):51-76.

Turner BS (2006) British sociology and public intellectuals: Consumer society and imperial decline. The British Journal of Sociology 57 (2):169-188.

Wolfinbarger M \& Gilly MC (2001) Shopping online for freedom, control, and fun. California management review 43 (2):34-55.

Okiriswandani F (2013) Gaya hidup santai mahasiswa (Studi pada mahasiswa Universitas Negeri penikmat coffe shop di Starbucks Coffee). Jurnal Sosial dan Politik 2 (1). 